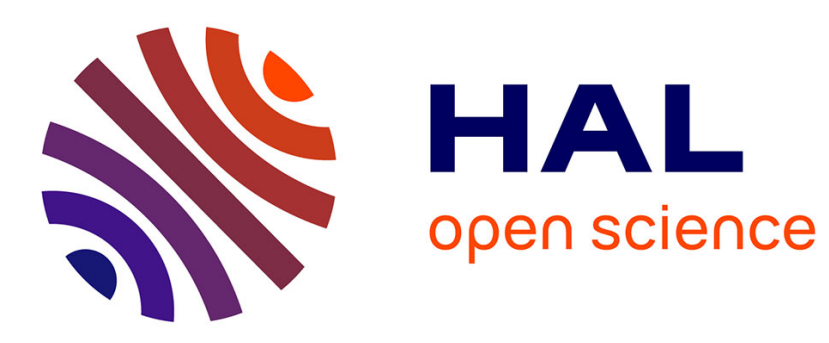

\title{
Multimetallic Nanoparticles Prepared by Redox Processes Applied in Catalysis
}

Florence Epron, Catherine Especel, Gwendoline Lafaye, Patrice Marcot

\section{To cite this version:}

Florence Epron, Catherine Especel, Gwendoline Lafaye, Patrice Marcot. Multimetallic Nanoparticles Prepared by Redox Processes Applied in Catalysis. Didier Astruc. Nanoparticles and Catalysis, Wiley, pp.279-302, 2007, 9783527315727. 10.1002/9783527621323.ch9 . hal-03179263

\section{HAL Id: hal-03179263 https://hal.science/hal-03179263}

Submitted on 24 Mar 2021

HAL is a multi-disciplinary open access archive for the deposit and dissemination of scientific research documents, whether they are published or not. The documents may come from teaching and research institutions in France or abroad, or from public or private research centers.
L'archive ouverte pluridisciplinaire HAL, est destinée au dépôt et à la diffusion de documents scientifiques de niveau recherche, publiés ou non, émanant des établissements d'enseignement et de recherche français ou étrangers, des laboratoires publics ou privés. 
Plurimetallic nanoparticles prepared by redox chemistry

\section{for applications in catalysis}

Florence Epron*, Catherine Especel, Gwendoline Lafaye and Patrice Marécot.

Laboratoire de Catalyse en Chimie Organique (UMR6503 CNRS-Université de Poitiers),

Bâtiment de chimie, 40 avenue du recteur Pineau, 86022 Poitiers Cedex- France

* Corresponding author

Dr Florence Epron

florence.epron.cognet@univ-poitiers.fr (e-mail) 


\begin{abstract}
This chapter deals with the preparation of plurimetallic nanoparticles by redox chemistry for application in catalysis. In a first part, the theoretical aspect of this technique will be briefly described. The second part will be devoted to the practical aspects of this preparation method. Then, some applications of the resulting catalysts in the synthesis of organic chemicals, in environmental catalysis and in catalysis for energy will be presented.
\end{abstract}

\title{
INTRODUCTION
}

Since the introduction of Pt-Re catalyst for naphtha reforming, bimetallic and multimetallic catalysts have been attracting much attention in order to improve the selectivity and the stability of metallic active sites. However, the catalytic performances of the supported nanoparticles strongly depends on the preparation method. Whereas classical coimpregnation and successive impregnation techniques lead to an unpredictable deposition of the two metals, different methods were developed to favour the metal-metal interactions, among them the redox reactions in aqueous phase can be mentioned $[1,2,3,4]$.

This chapter deals with the preparation of plurimetallic nanoparticles by redox chemistry for application in catalysis. In a first part, the theoretical aspect of this technique will be briefly described. The second part will be devoted to the practical aspects of this preparation method. Then, some applications of the resulting catalysts in the synthesis of organic chemicals, in environmental catalysis and in catalysis for energy will be presented.

\section{THEORETICAL ASPECTS}

Whatever the technique used, the first step always consists of the preparation of a monometallic catalyst, which is generally activated by calcination and reduction. Then, the monometallic catalyst is introduced in the preparation reactor, reduced and the liquid phase is added to obtain a suspension of the catalyst. The metal constituting the monometallic catalyst is denoted as "parent" metal. The last step of the preparation procedure consists of the introduction of the modifier in solution in the form of a precursor salt. The different techniques differ according to this last step. Indeed, four preparation methods can be chosen 
as a function of the reversible Nernst potential of the different species involved in the preparation procedure, namely (i) the direct redox reaction between the "parent" metal and the oxidized form of the modifier, (ii) the redox reaction between an adsorbed reducing agent and the oxidized form of the modifier, (iii) the catalytic reduction and (iv) the underpotential deposition. According to these techniques, trimetallic catalysts can also be prepared by replacing the parent monometallic catalyst by a bimetallic one. This can be extended to the preparation of multimetallic catalysts.

\subsection{Preparation of bimetallic catalysts by direct redox reaction}

In this case, metal-metal interactions result from surface redox reactions between the prereduced parent metal $\mathrm{M}$ and the oxidized form of the modifier $\mathrm{M}^{\prime} \mathrm{Z}^{\prime}$.

The half reaction corresponding to the oxidation of the parent metal is the following:

$$
\mathrm{M} \rightleftarrows \mathrm{M}^{\mathrm{Z}+}+\mathrm{ze}^{-}
$$

According to the Nernst equation, the equilibrium potential $\left(E_{\mathrm{M}^{\mathrm{z}} / \mathrm{M}}\right)$ of the reversible oxidation of $\mathrm{M}$ is expressed as the following :

$$
E_{\mathrm{M}^{\mathrm{Z}+\mathrm{M}}}=\mathrm{E}_{\mathrm{M}^{\mathrm{Z}+} / \mathrm{M}}^{\circ}+\frac{\mathrm{RT}}{\mathrm{zF}} \operatorname{Ln} \frac{\mathrm{a}_{\mathrm{M}^{\mathrm{Z}+}}}{\mathrm{a}_{\mathrm{M}}}
$$

where $\mathrm{a}_{\mathrm{M}^{\mathrm{z}}}$ and $\mathrm{a}_{\mathrm{M}}$ are the activities of oxidized $\left(\mathrm{M}^{\mathrm{Z}+}\right)$ and reduced $(\mathrm{M})$ species, respectively, $E_{\mathrm{M}^{\mathrm{Z}+} \mathrm{M}}$ is the standard reduction potential, $\mathrm{R}$ the gas constant, $\mathrm{F}$ the faraday constant and $\mathrm{T}$ the temperature.

In the same way, the equilibrium potential of the reversible reduction of the modifier in oxidized form $\left(\mathrm{M}^{\mathrm{Z}}+\right)$ is given by :

$$
\mathrm{E}_{\mathrm{M}^{z^{\prime}+/ \mathrm{M}^{\prime}}}=\mathrm{E}_{\mathrm{M}^{\prime z^{+} / \mathrm{M}^{\prime}}}^{\circ}+\frac{\mathrm{RT}}{\mathrm{Z}^{\prime} \mathrm{F}} \operatorname{Ln} \frac{\mathrm{a}_{\mathrm{M}^{z^{+}}}}{\mathrm{a}_{\mathrm{M}^{\prime}}}
$$

If the value of the change in Gibbs free energy $(\Delta \mathrm{G})$ given by:

$$
\Delta \mathrm{G}=-\mathrm{zz} F\left(\mathrm{E}_{\mathrm{M}^{\underline{\alpha}+} / \mathrm{M}^{\prime}}-\mathrm{E}_{\mathrm{M}^{\mathrm{z}} / \mathrm{M}}\right)
$$

is negative $\mathrm{M}^{\prime} \mathrm{Z}^{\prime}+$ will be reduced by the metal $\mathrm{M}$ as follows :

$$
\mathrm{z}^{\prime} \mathrm{M}+\mathrm{z} \mathrm{M}^{\mathrm{z}^{\prime+}} \rightarrow \mathrm{zM}^{\prime}+\mathrm{z}^{\prime} \mathrm{M}^{\mathrm{z}^{+}}
$$

The system will tend to an equilibrium that corresponds to the equality of the two reversible potentials $\mathrm{E}_{\mathrm{M}^{\mathrm{Z}^{\prime}+} \mathrm{M}^{\mathrm{M}}}$ and $\mathrm{E}_{\mathrm{M}^{\mathrm{z+}} / \mathrm{M}}$. In this way, surface atoms $\mathrm{M}$ of the metallic particles are replaced by atoms M' of the modifier. This method is used to deposit metals with high standard reduction potential, such as noble metals, onto nanoparticles of metals with a 
lower standard reduction potential. Many examples of the use of direct redox reactions in the preparation of bimetallic catalysts could be quoted such as the modification of (i) copper catalysts by ruthenium [5, 6], by platinum [7, 8], by palladium [7, 8] or by gold [7], (ii) platinum by gold $[9,10,11]$ or palladium by platinum [12]. As an example, platinum $\left(\mathrm{E}^{\circ} \mathrm{Pt}^{2+} / \mathrm{Pt}\right.$ $=1.188 \mathrm{~V} / \mathrm{SHE}$ ) can be deposited onto copper particles considering copper in the metallic state $\left(\mathrm{E}^{\circ}{ }_{\mathrm{Cu}}^{2+} / \mathrm{Cu}=0.34 \mathrm{~V} / \mathrm{SHE}\right)$ according to the reaction:

$$
\mathrm{Cu}(\mathrm{s})+\mathrm{Pt}^{2+}(\mathrm{aq}) \rightarrow \mathrm{Cu}^{2+}(\mathrm{aq})+\mathrm{Pt}(\mathrm{s})
$$

Of course, if the precursor salt is introduced in the form of a complex, the stability constant of the complex must be taken into account. For instance, the standard reduction potential of platinum in chloroplatinic acid solution $\left(\mathrm{E}^{\circ} \mathrm{PtCl}_{6}^{2-} / \mathrm{Pt}=0.744 \mathrm{~V} / \mathrm{SHE}\right)$ is lower than that of the $\mathrm{Pt}^{2+} / \mathrm{Pt}$ couple and corresponds to the half reaction :

$$
\mathrm{PtCl}_{6}^{2-}(\mathrm{aq})+4 \mathrm{e}^{-} \Longleftarrow \mathrm{Pt}(\mathrm{s})+6 \mathrm{Cl}^{-}(\mathrm{aq})
$$

\subsection{Redox reactions of adsorbed species in the preparation of bimetallic catalysts}

This method is called in the literature "recharge" or "refilling" method [13, 9, 10, 12, 14, $15,11,16]$ or "adsorption of metallic ions via ionization of adsorbed hydrogen" $[17,18 ; 19$; $20 ; 21 ; 22 ; 23,24]$.

In this method, the ions of the modifier are reduced by a reagent (most commonly hydrogen), which preadsorbs selectively on the metal. This requires the parent metal to chemisorb hydrogen. Then, the adsorbed reducing agent, for instance hydrogen, can be considered as a source of electrons according to the following reaction:

$$
\mathrm{H}_{\mathrm{ads}} \rightarrow \mathrm{H}^{+}+\mathrm{e}^{-}
$$

Then the reduction of the modifier $\mathrm{M}^{\mathrm{z}^{\prime+}}$ can occur:

$$
\mathrm{M}^{\prime \mathrm{Z}^{\prime+}}+\mathrm{z}^{\prime} \mathrm{H}_{\mathrm{ads}} \rightarrow \mathrm{M}_{\mathrm{ads}}^{\prime}+\mathrm{z}^{\prime} \mathrm{H}^{+} \text {. }
$$

In this method, the prereduced monometallic catalyst suspended in aqueous solution is treated with hydrogen until the surface of the catalyst is completely saturated by adsorbed hydrogen. Then, the reactor is flushed with inert gas to remove the hydrogen dissolved in the electrolyte. After outgassing, a deoxygenated solution containing the precursor salt of the modifier is added.

Many examples are reported in the literature where platinum, palladium or ruthenium are used as parent metals, such as Pt-Cu [17, 14], Pt-Au [18, 16, 11], Pt-Pd [25], Pt-Re [26, 27], Pt-Ru [21], Pt-Bi [19] , Pt-Pb [20], Pd-Pt [12], Pd-Cu [22-1, 15], Pd-Ge [23, 24].

\subsection{Catalytic reduction in the preparation of bimetallic catalysts}


As for the "refilling" method described in the previous paragraph, the chemisorption properties of the parent metal are used to activate hydrogen, but the deposition of the modifier is performed under hydrogen flowing. According to the thermodynamics, molecular hydrogen in solution can reduce any metallic salt that has a redox potential greater than that of the $\mathrm{H}^{+}$/ $\mathrm{H}_{2}$ couple. However, at room temperature, the reduction of several metallic salts is kinetically limited. Then, the catalytic properties of the metal are used to increase the rate of reduction of the additive ion by means of a reducing agent, such as hydrogen, in solution. Thus the metal plays the role of the catalyst in the redox reaction. In such conditions, the additive should be deposited on the catalytic site that is active for the reduction reaction. However, transfer of electrons from the parent metal to the metallic modifier could also favour the formation of three-dimensional agglomerates. In the same way, if the parent catalyst consists of a metal supported on a conductor, the additive will deposit competitively on the parent metal and on the support.

To date, the catalytic reduction has been mainly used to modify platinum by rhenium $[26,28,29,30,31]$ or by copper [32, 33, 34], palladium by copper [34-36], by silver [34], by gold [34] or by tin [37], ruthenium by copper [5] or lead [38], or rhodium by copper [39] or by germanium [40, 41]. Most recently, trimetallic catalysts were also prepared by catalytic reduction, such as Pt-Ir-Sn [42, 43], Pt-Ir-Ge or Pt-Re-Ge [44] or Pd-Sn-Au [45].

\section{4 Underpotential deposition}

Underpotential deposition consists of the formation of a metal submonolayers at potentials more positive than the reversible Nernst potential, before the bulk deposition can occur [2, 46-50]. This technique is also called "adatom deposition" [51] or "adsorption of metal atoms" [52].

If the bulk deposition of a metal $\mathrm{M}^{\prime}$ occurs according to the reaction,

$$
\mathrm{M}^{\mathrm{z}^{\prime+}}+\mathrm{z}^{\prime} \mathrm{e}^{-} \rightleftarrows \mathrm{M}^{\prime}
$$

the activity of the deposited metal is assumed to be equal to one. In this case, the equilibrium potential is given by the following equation:

$$
\mathrm{E}_{\mathrm{M}^{\prime \mathrm{z}^{\prime}+} / \mathrm{M}^{\prime}}=\mathrm{E}_{\mathrm{M}^{\prime} \mathrm{z}^{\prime}+\mathrm{M}^{\prime}}+\frac{\mathrm{RT}}{\mathrm{z}^{\prime} \mathrm{F}} \operatorname{Ln} \mathrm{a}_{\mathrm{M}^{\prime \mathrm{z}^{\prime}+}}
$$

When $\mathrm{M}^{\prime}$ is deposited in submonolayer $\left(\mathrm{M}_{\mathrm{ML}}^{\prime}\right)$ on the metal $\mathrm{M}$, the coverage $\theta$ of $\mathrm{M}$ by $\mathrm{M}^{\prime}$ and then the activity of $\mathrm{M}^{\prime}$ in submonolayer is lower than one. The activity of $\mathrm{M}^{\prime}$ is given by:

$$
\mathrm{a}_{\mathrm{M}_{\mathrm{ML}}^{\prime}}=\gamma \mathrm{M}^{\prime} \theta
$$


where $\gamma_{\mathrm{M}^{\prime}}$ is the activity coefficient of $\mathrm{M}^{\prime}$.

For the deposition of a submonolayer of metal, the equilibrium potential can be given by :

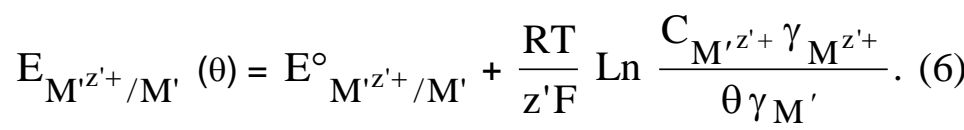

where $\mathrm{C}_{\mathrm{M}^{\prime z^{+}}}$is the concentration of the precursor salt $\mathrm{M}^{\mathrm{z}} \mathrm{z}^{+}$.

The equilibrium potential $\mathrm{E}(\theta)$ of the submonolayer is always more positive than the Nernst potential of a bulk deposition. As a result, an underpotential deposition (UPD) of adatoms of $\mathrm{M}^{\prime}$ on $\mathrm{M}$ can occur. Underpotential deposition leads to the formation of submonolayers before the three dimensional bulk deposition occurs and the coverage varies with the potential and time of deposition. UPD is characterized by the existence of adatoms. The simplest methods for investigating UPD are electrochemical.

Examples of the use of UPD technique are the modification of platinum catalysts by copper [52, 53, 54, 55, 56, 57, 58], arsenic [59], by gold [60], by iron [61], by lead or tin [62, 63], or by rhodium [64] and the modification of palladium by copper [22], by germanium [23] or by iron $[65,66,67]$. The majority of these examples concern the modification of electrodes, which is not the subject of this chapter.

\section{PRACTICAL ASPECT}

\subsection{Stability of supported catalysts in aqueous phase}

It is mentionned in Section 1 that the preparation of bimetallic nanoparticles by surface redox reaction occurs under controlled atmosphere between a "parent" monometallic catalyst and the cation of the second metal dissolved in aqueous solution. However, the immersion of the parent catalyst in the solution may induce a modification of the metal particle size before the introduction of the ion of the second metal. In an aqueous medium, water molecules could penetrate between the metal-support interface and induce the migration of metal crystallites. Moreover, water and gas, for instance hydrogen, can adsorb and dissociate on metals leading to a modification of their electronic properties. Consequently, it is important to study the stability of supported monometallic catalysts in aqueous phase environment under gas atmosphere at room temperature. The influence of different parameters was examined in the literature, such as the initial oxidation state of the metal, the $\mathrm{pH}$ of the solution, the presence of chloride anions in the solution and the nature of the gas atmosphere.

The stability of supported metal catalysts treated in aqueous media under gas atmosphere at room temperature depends on the initial oxidation state of the metal, i.e. preoxidized or in- 
situ reduced. Indeed, the immersion in liquid phase of a prereduced platinum supported catalyst then exposed to air induces a more or less important sintering of the metal depending on various parameters such as the nature of the support, the $\mathrm{pH}$ of the solution,...[68]. An in situ reduction before catalyst immersion in an aqueous solution allows to prevent or to restrict the metal accessibility loss.

\section{Table 1.}

The sintering of the parent metal may result from the immersion in the aqueous medium only or from both the immersion in the solution and the nature of the bubbling gas. Table 1 shows for example that the metallic dispersion loss of a Pt/silica catalyst is more marked in the presence of hydrogen, compared to nitrogen, whatever the initial $\mathrm{pH}$ of the solution. This phenomenon results from the metal-H binding energy that can be far higher than that of the metal-metal $[69,70]$. This metal-H interaction would weaken the metal-support interaction and so the metallic particles would become unstable and would migrate onto the support leading to platinum nanoparticle growth. This sintering is even stronger in presence of $\mathrm{Cl}^{-}$ ions (acidic solution) or $\mathrm{OH}^{-}$ions (basic solution), which can interact with metal particles inducing also a decrease of the electronic density of the metal [12, 68, 70].

These effects are all the more pronounced as the metal-support interactions of the parent catalyst are weak. In other words, when the metal-support interactions are prevailing, the metallic particles would remain stable. Examples (Table 1) are reported in the litterature for platinum [68, 70], palladium [37] and rhodium [40] showing that silica leads to a more severe sintering than alumina. Indeed, it appears that the platinum-support interactions decrease following the sequence: $\mathrm{Al}_{2} \mathrm{O}_{3}>\mathrm{C}>\mathrm{SiO}_{2}$ [71]. Furthermore, it was observed aggregates of parent metal particles on catalysts samples supported on silica and treated in aqueous media under hydrogen atmosphere and dried at $120^{\circ} \mathrm{C}$, contrary to alumina support $[70,40]$. The sintering of the parent metal would occur via crystallite migration onto the support.

In the course of the preparation of bimetallic catalysts by redox reaction, the modifier itself can induce a modification of the metal particle size. Then, sintering of Pt can occur during redox reactions under hydrogen atmosphere in the presence of Au which has a higher standard redox potential than the one of $\mathrm{Pt}[9]$. That sintering is explained by the oxidation of platinum atoms of low coordination number and a further reduction by hydrogen of those oxidized forms on platinum atoms of high coordination number. In other hand, the deposition of germanium restricts the sintering of rhodium particles which is observed when a parent rhodium/silica catalyst was immersed in an aqueous solution under hydrogen atmosphere. An 
explanation of this phenomenon could be the consumption of hydrogen activated on rhodium surface by the reduction of the germanium salt [40]. The same phenomenon was observed for palladium/alumina modified by tin [37].

In conclusion, the treatment of supported catalysts in aqueous medium seems therefore unfavorable to the presence of well dispersed nanoparticles. Nevertheless, an in-situ reduction of the parent catalyst allows one to prevent or restrict metal sintering, depending on the nature of the support. However, in the absence of any contact of the catalyst with air, many parameters can also influence the metal particle size. Then, for example it is better to avoid especially very acidic $(\mathrm{pH}=2)$ or very basic $(\mathrm{pH}=10)$ solutions $[12,70]$.

\section{2. Study of the deposition reaction}

\subsubsection{On bulk catalysts}

In the case of powder bulk catalysts, $\mathrm{Cu}$ Raney was modified by direct redox reaction between reduced copper and the salt of a noble metal $\mathrm{M}(\mathrm{Ru}, \mathrm{Pt}$ and $\mathrm{Au})[5,7]$. Typically the $\mathrm{Cu}-\mathrm{M}$ bimetallic catalysts were obtained by mixing a freshly prepared $\mathrm{Cu}$ Raney with an aqueous solution of the noble metal salt. When the amount of $\mathrm{M}$ is introduced in excess compared to the number of copper surface atoms, it appears that ruthenium deposit is restristed to approximatively $1 / 3$ of the copper surface atoms. For platinum and gold, a deposit larger than a monolayer is obtained indicating that subsurface copper atoms are involved in direct redox reaction. This result is explained by the lower potential difference between copper and ruthenium compared to that of copper and platinum or gold [7]. However, the reactions involved in the direct redox reaction may be not so simple as indicated in the theoretical part (section 1). A typical time distribution of ion concentrations in solution during the preparation of $\mathrm{Cu}-\mathrm{Pt}$ is shown on Figure 1. It can be observed that platinum ions disappeared very rapidly from the solution while in the same time copper ions are formed and their concentration reached a maximum. Further on, the soluble copper fraction decreased down to a plateau. The $\mathrm{Cu}^{\mathrm{n}+}$ species concentrations at this plateau are not representative of the redox reaction but are determined by the solubilities of the different copper ions in the solution, depending on the anion accompanying the metal precursor [7]. Likewise, Pt Adams was modified by gold added by direct and refilling redox reactions [9].

Recently, novel catalysts were obtained by impregnation of $\mathrm{Cu}-\mathrm{Pt}$ or $\mathrm{Cu}-\mathrm{Pd}$ nanospheres on active carbon by incipient-wetness technique. The bimetallic species were obtained by direct redox reaction between the surface of bulk copper nanospheres and Pt or Pd salts. [8].

\section{Figure 1.}




\subsubsection{On supported catalysts}

The supported catalysts can be modified either by noble metals or based metals.

For noble modifiers, two techniques were mainly used: the direct redox and the refilling method with preadsorbed hydrogen $[9,12,72,11]$. The different supports presented in the litterature are silica $[9,72]$, alumina [12] and active carbon [11]. It should be pointed out that the preparation of $\mathrm{Pt}-\mathrm{Au} / \mathrm{SiO}_{2}$ bimetallic catalysts using hydrogen preadsorbed on platinum is a complex reaction involving simulteously reduction of $\mathrm{AuCl}_{4}{ }^{-}$by hydrogen and direct oxidation of metallic platinum. According to the difference in initial rates $\left(10^{19}\right.$ versus $10^{17}$ atoms of $\mathrm{Au}$ reduced per $\mathrm{s}$ and per $\mathrm{m}^{2}$ of $\mathrm{Pt}$ ) pointed out in ref. [9], it can be assumed that during the preparation of $\mathrm{Pt}-\mathrm{Au}$ bimetallic catalysts, for low gold coverages (when the quantity of hydrogen is sufficient to reduce all the introduced gold ions), gold is reduced by preadsorbed hydrogen. On the other hand, for higher gold concentrations, reduction by preadsorbed hydrogen and then by direct oxidation of platinum can occur [9].

When the modifier is a based metal, the mainly used redox reaction is the catalytic reduction. Nevertheless, the "refilling" method with preadsorbed hydrogen was utilized in some cases. For example, platinum over alumina reforming catalyst was modified by rhenium via this technique [26]. However, the rhenium deposit is limited by the amount of hydrogen irreversibly adsorbed on surface platinum. Then, many sucessive "refilling" steps must be performed in order to deposit the amount of Re needed for usual Pt-Re reforming catalysts. On the other hand, the catalytic reduction allows one to deposit large amounts of rhenium in one step because the reaction is carried out under hydrogen flow [26, 29]. This method was also used for the preparation of different bimetallic catalysts, such as Rh-Ge [40, 41-1], Pt-Ru [73], Pd-Cu [35, 34], Pt-Cu [34, 33], Pd-Sn [37], Ru-Pb [38], Pt-Sn [42, 43], or trimetallic catalysts: Pt-Ir-Sn [42, 43], Pt-Ir-Ge [44], Pt-Re-Ge [44], Pd-Sn-Au [45], Pt-Ru-Sn [73] and Pt-Ru-Mo [73].

\section{Figure 2.}

In the course of the catalytic reduction, deposition of the second metal (or the third) can occur on both the parent metal and the support depending on the nature of the support and the operating conditions. Effectively, in the case of bimetallic Rh-Ge [40] and Pt-Sn [37] catalysts, it was observed that the amount of Ge or Sn deposited is higher on alumina than on silica supported catalysts (Figure 2). Furthermore, the same experiments carried out under 
nitrogen flow do not lead to additive deposition on silica supported catalysts, while some deposit occurs on alumina supported catalysts. This result was explained by the adsorption of the additive anionic species in an acidic medium on alumina support contrary to silica support, according to their isoelectric points. Moreover, the greater additive deposition under hydrogen flow compared to that observed under nitrogen bolstered that hydrogen activated on the parent metal particles participates to the deposition reaction.

In order to decrease the contribution of the support, different parameters can be optimized:

- the deposition on the metal by catalytic reduction being faster than the one on the support, the reaction time can be limited to some minutes [42, 26, 29],

- a competitive adsorbate can be added to the reaction mixture. For example the addition of citric acid in the acid medium allowed one to decrease tin deposit on alumina support in the course of Pt-Sn and Pt-Ir-Sn reforming catalyst preparations $[42,43]$,

- the nature of the precursor and especially the oxidation state of the additive. For example the catalytic reduction is faster with $\mathrm{Re}^{4+}$ than with $\mathrm{Re}^{7+}$, which promotes $\mathrm{Re}$ deposition on Pt for a short reaction time [26],

- $\quad$ the nature of the reducer [74].

Other parameters can also strongly influence the kinetics and the extent of a modifier deposition by catalytic reduction, such as the partial pressure of hydrogen, the temperature of reaction, the concentration of the additive salt and the dispersion of the parent catalyst [26].

\section{3. Characterization of the metal-metal interaction}

\subsubsection{Model reactions}

Different model reactions were used in order to put in evidence the interaction between the modifier and the parent metal. It was observed that an inert additive introduced by redox reaction generally poisons more or less the activity of the parent metal or strongly modifies the selectivity of the reaction, which indicates a deposition of the additive on the parent metal. For example, a decrease of activity for structure insensitive reactions, such as toluene hydrogenation [40] or cyclohexane dehydrogenation [42, 75] proves the existence of bimetallic nanoparticles. Likewise, in the case of 2,2-dimethylpropane reaction, the modification of both the selectivity and the apparent activation energy, demonstrates an interaction between $\mathrm{Pd}$ and $\mathrm{Au}$ introduced by direct redox reaction. Conversely, no modification was observed on the catalysts prepared by incipient wetness coimpregnation [72]. 
Another useful probe is the cyclopentane hydrogenolysis for indicating the extent of Pt-Re alloying on reforming catalysts, the alloy being intrinsically more active than either pure metal $[76,77]$. On Figure 3, the synergy in the activity shows a great interaction between the two metals for Pt-Re catalysts prepared by catalytic reduction [29].

\section{Figure 3.}

\subsubsection{Adsorption of probe molecules}

The adsorption of probe molecules followed by different techniques allowed one to prove the metal-metal interaction for catalysts prepared by redox reactions. For example, by chemisorption measurements, it was observed a decrease of the total amount of adsorbed $\mathrm{H}_{2}$ with an increasing germanium content introduced by catalytic reduction on parent rhodium catalysts [78]. As TEM characterization showed a comparable mean particle size for all the catalysts, such evolution suggests that Ge covers the Rh surface [40]. These results were consistent with those obtained by FTIR spectroscopic studies of adsorbed CO showing a decrease of chemisorbed CO [78]. Moreover, modifications and band shifts of FTIR spectra of adsorbed $\mathrm{CO}$ have indicated a close contact between the two metals in $\mathrm{Pt}-\mathrm{Cu}, \mathrm{Pt}-\mathrm{Ag}, \mathrm{Pd}-$ $\mathrm{Cu}, \mathrm{Pd}-\mathrm{Ag}$ and $\mathrm{Rh}-\mathrm{Ge}$ catalysts prepared by catalytic reduction $[34,78]$.

The TPR under hydrogen is a technique mainly used to characterize metallic phases. In the case of $\mathrm{M}_{1}-\mathrm{M}_{2}$ bimetallic catalysts, a reduction peak usually appears between those of pure metals $M_{1}$ and $M_{2}$, this peak being all the more significant as the interaction $M_{1}-M_{2}$ is high. Bimetallics prepared by redox reactions show this characteristic (Figure 4) [34, 42, 41, 33]. Nevertheless, when a competitive adsorption of the additive occurs on the support, a hydrogen consumption corresponding to the reduction of the isolated species appears at higher temperature $[33,34,42,41]$. The presence of these species on the support also allowed one to explain the variations in the Brönsted and Lewis acidity of reforming Pt/alumina or PtIr/alumina modified by Ge [43]. The model reaction to determine the Brönsted acidity was the 3,3-dimethylbut-1-ene isomerization while FTIR adsorption of pyridine was used to determine the number of Lewis acid sites.

\section{Figure 4.}

\subsubsection{Physical techniques}

Some physical techniques were also used to characterize metallic nanoparticles prepared by surface redox reactions, for examples:

- $\quad$ XPS analysis were performed on stored $\mathrm{Cu}-\mathrm{Au}$ catalysts prepared by direct redox reaction with no subsequent reduction by hydrogen. After contacting the reduced copper catalyst with the Au salt, Au appears to be deposited in metallic state [7]. 
- XRD technique, which allows one to determine the composition of crystallized compounds, pointed out that bimetallic aggregates are formed for $\mathrm{Pt}-\mathrm{Au}$ prepared by direct redox or refilling method [10] and for Pt-Sn prepared by catalytic reduction [37].

- $\quad$ EXAFS measurements for Pd-Pt systems prepared either by direct redox or refilling method indicated the presence of platinum in the vicinity of palladium for both preparations [12].

- $\quad$ TEM coupled with EDX microanalysis was carried out on Pd or Pt modified by $\mathrm{Cu}$, $\mathrm{Ag}$ and $\mathrm{Au}$ [34], Pd-Sn [37], Pd-Cu [35], Rh-Ge [40], Pt-Ru-Sn and Pt-Ru-Mo (Figure 5) [73], Pd-Sn-Au and Pt-Sn-Au [45] to collect more information on metallic particles in terms of particle size and composition. The catalysts prepared by redox reactions showed that the parent metal is always associated to the additive, but that one can be found isolated for supports which are able to adsorb the modifier,

- Mössbauer spectroscopy showed that on silica supported catalysts, only Pd-Sn solid solutions or alloys are present, whereas, on alumina supported catalysts, tin is present at the interface between the support and palladium, or alone on the support, due to its high affinity for alumina [37]. On trimetallic $\mathrm{Pd}-\mathrm{Sn}-\mathrm{Au}$, a trimetallic phase was also evidenced on silica support [45].

\section{Figure 5.}

All these techniques are valuable in assessing the degree of alloying. By combining some of these techniques, it was possible to go further in the determination of the location of the deposit $\left(\mathrm{M}_{2}\right)$ on parent metal particles $\left(\mathrm{M}_{1}\right)$. Effectively, in the course of redox reactions, the deposit exhibited a selectivity depending on the relative redox potential of $\mathrm{M}_{1}{ }^{\mathrm{n}+} / \mathrm{M}_{1}$ and $\mathrm{M}_{2}{ }^{\mathrm{n}+} / \mathrm{M}_{2}$. Then, when the difference of potentiel is low such as for the Pt-Au, Pd-Pt or Cu-Ru couples, the additive was preferentially deposited on low coordination sites (corners, edges,...) $[9,12,7,6]$, while when the difference of potentiel is high, for examples with $\mathrm{Cu}-\mathrm{Pt}, \mathrm{Cu}-\mathrm{Au}$, all $\mathrm{Cu}$ sites were involved in the redox reaction [7].

\subsection{Influence of the gaseous environment on the nanoparticle stability}

The catalytic properties are strongly influenced by the activation mode of the catalysts. Then, the influence of different gas treatments at the end of the additive deposition by redox reactions was examined. These treatments may lead to a sintering or a segregation of the metals. 
After preparation by catalytic reduction and after drying overnight at $70^{\circ} \mathrm{C}$ under nitrogen flow, $\mathrm{Pt}-\mathrm{Cu} / \mathrm{Al}_{2} \mathrm{O}_{3}$ catalysts were tested as is for the nitrate reduction or after air exposure at ambient temperature [33]. The highest activity was obtained in the later case. This allows one to increase $\mathrm{Pt}$ accessibility in bimetallic catalysts, whereas the coverage of $\mathrm{Pt}$ particles by $\mathrm{Cu}$ in the just prepared catalysts is probably too important. Conversely, a poor activity is obtained after an oxidation at $400^{\circ} \mathrm{C}$, the segregation between the two metals being too important with a migration of copper towards the alumina support. Likewise, a calcination at $450^{\circ} \mathrm{C}$, followed by a reduction at $500^{\circ} \mathrm{C}$ greatly diminishes Pt-Re metal-metal interaction [Pieck1995, 29). Then, the maximum in activity observed for cyclopentane hydrogenolysis (Figure 3 ) is shifted to higher rhenium contents after calcination [29].

More often the samples are directly reduced under hydrogen at various temperatures after additive deposition and drying. It appeared that a direct reduction with a high heating-rate ( $\left.10^{\circ} \mathrm{C} \cdot \mathrm{min}^{-1}\right)$ under hydrogen leads to a sintering whereas a low heating-rate $\left(\sim 2^{\circ} \mathrm{C} \cdot \mathrm{min}^{-1}\right)$ prevents or restricts it [68]. Otherwise, it was observed that the hydrogenating properties of bimetallic $\mathrm{Rh}-\mathrm{Ge} / \mathrm{Al}_{2} \mathrm{O}_{3}$ catalysts prepared by catalytic reduction greatly depend on the reduction temperature and go through an optimum as a function of the reduction temperature which depends on the germanium content [41]. This phenomenon can be explained by both a change of the reduction degree of germanium in contact with rhodium and a Ge enrichment of bimetallic particles resulting from a migration at high temperature of germanium species deposited on the alumina support. In the case of $\mathrm{Pt}-\mathrm{Cu}$ samples prepared by catalytic reduction, a treatment under hydrogen at high temperature $\left(400^{\circ} \mathrm{C}\right)$ induced a surface enrichment of Pt, copper atoms diffusing inwards [33].

The effect of an oxidation step after a first reduction under hydrogen was also examined. It appeared that the air exposure of $\mathrm{Rh}-\mathrm{Ge} / \mathrm{Al}_{2} \mathrm{O}_{3}$ catalysts prepared by catalytic reduction results in an irreversible modification of the metallic phase, leading to a segregation of the two metals $[41,78]$. Likewise, hydrogenation of isoprene and FTIR analysis have shown that air exposure of Pd-Fe catalysts prepared using preadsorbed hydrogen modifies the nature of the interaction between $\mathrm{Fe}$ and the Pd sites of low coordination, leading to inactive species for the reaction [65]. The detrimental effect of air exposure was also observed for Pt-Au catalysts, resulting in an irreversible rearrangement of the metallic surface created by the redox reaction. This rearrangement effect was evidenced by X-ray diffraction and by high resolution electron microscopy studies [16]. 


\section{APPLICATIONS IN THE SYNTHESIS OF ORGANIC CHEMICALS}

In the field of organic chemistry, the main applications using bimetallic catalysts prepared by surface redox reactions were developed in selective hydrogenation and hydrogenolysis reactions.

\subsection{Selective hydrogenation}

The selective hydrogenation of organic molecules having different functional groups able to be hydrogenated is one of the main goals in synthesis processes for organic compounds.

\subsubsection{Competition between $\mathrm{C}=\mathrm{C}$ and $\mathrm{C}=\mathrm{O}$ bonds}

An interesting case was studied with the carvone molecule (terpenic monocyclic ketone), since it has three different functional groups which can be hydrogenated: one $\mathrm{C}=\mathrm{O}$ group and two $\mathrm{C}=\mathrm{C}$ groups (endocyclic and exocyclic ones), which display different chemical reactivities for hydrogenation (Fig. 6). Bimetallic $\mathrm{Pd}-\mathrm{Cu} / \mathrm{SiO}_{2}$ catalysts prepared by the refilling method favoured the selective formation of carvotanacetone (unsaturated ketone), whereas the same systems prepared by coimpregnation led to carvomenthone (saturated ketone) [15]. These different selectivity behaviours were a result of the Pd sites where the $\mathrm{Cu}$ was deposited and then an effect of the method of preparation.

\section{Figure 6}

By FTIR of adsorbed $\mathrm{CO}$, a preferential deposit of $\mathrm{Cu}$ on $\mathrm{Pd}$ sites of lower coordination was observed on the bimetallic catalysts prepared by redox reaction. On the contrary, in the coimpregnated systems, a random $\mathrm{Cu}$ distribution occurred on the dense $\operatorname{Pd}(111)$ planes. It was reported that the formation of carvotanacetone is produced mainly on the Pd sites of high coordination where the desorption of the molecule is favoured. The adsorption is stronger on low coordination sites, leading to a higher residence time of the molecule and then to further hydrogenation [79].

The performances of bimetallic $\mathrm{Rh}-\mathrm{Ge} / \mathrm{SiO}_{2}$ and $\mathrm{Rh}-\mathrm{Ge} / \mathrm{Al}_{2} \mathrm{O}_{3}$ catalysts prepared by catalytic reduction were measured for an another $\alpha, \beta$-unsaturated aldehyde namely citral (Fig. 7). The addition of $\mathrm{Ge}$ to $\mathrm{Rh}$ by surface redox reaction promoted the hydrogenation of citral to the unsaturated alcohols (geraniol/nerol), while the saturated aldehyde (citronellal) was the main product on the monometallic Rh catalyst [40]. 


\section{Figure 7}

Moreover, these redox catalysts were more active and selective than bimetallic $\mathrm{Rh}-\mathrm{Ge}$ systems prepared by successive impregnations. The citral conversion and the selectivity to unsaturated alcohols increased with the Ge content, this effect being the most obvious on alumina supported catalysts (Fig. 8). The selectivity enhancement on this last support in comparison with silica was explained by Ge deposited on the alumina support in the close vicinity of Rh nanoparticles during the catalytic redox reaction. These Ge species would be partially reduced during the reduction step of the catalyst and would promote the activation of the carbonyl group for hydrogenation. Then, the catalytic properties of the bimetallic Rh$\mathrm{Ge} / \mathrm{Al}_{2} \mathrm{O}_{3}$ catalysts prepared by redox reaction strongly depended on their reduction temperature, which must be optimised according to the Ge content and the nature of solvent used for the reaction [41].

\section{Figure 8}

The performances of bimetallic $\mathrm{Pd}-\mathrm{Ge} /$ carbon catalysts prepared by the refilling technique were also studied for the liquid phase hydrogenation of $\mathrm{C}=\mathrm{C}$ bonds conjugated with carbonyl or other functional groups (hydroxyl, carboxyl, nitrile...) [24]. The presence of the $\mathrm{Ge}^{\delta+}$ centers resulted mainly in changes in the adsorption of substrates and/or products of the studied reaction.

\subsubsection{Competition between $\mathrm{C}=\mathrm{C}$ bonds}

During isoprene hydrogenation, iron added by ionization of preadsorbed hydrogen promoted the activity of $\mathrm{Pd} / \mathrm{Al}_{2} \mathrm{O}_{3}$ catalysts while the opposite effect was observed when iron was introduced by coimpregnation or successive impregnations [65, 66]. These different behaviours were the result of an electron transfer from $\mathrm{Fe}$ to $\mathrm{Pd}$, and of a deposition of $\mathrm{Fe}$ adatoms on the surface of $\mathrm{Pd}$ nanoparticles by redox reaction while the coimpregnated catalysts would lead to alloy formation with a strong Pd surface segregation.

Other bimetallic systems containing Pd were studied for vegetable oil hydrogenation in order to produce lubricants. Main unsaturated fatty acids in vegetable oils are linolenic acid (C18:3), linoleic acid (C18:2) and oleic acid (C18:1). A partial hydrogenation of rapeseed oil to the $\mathrm{C} 18: 1$ acid (keeping the cis isomer form) is needed to obtain oils with a low sensitivity to oxygen. Moreover, the trans $\mathrm{C} 18: 1$ and the totally saturated (stearic acid, C18:0) 
compounds must be avoided since they are still solid at ambient temperature. $\mathrm{Pd} / \mathrm{SiO}_{2}$ catalysts modified by addition of $\mathrm{Cu}$ and $\mathrm{Pb}$ by catalytic reduction were investigated for the selective hydrogenation of sunflower oil at low temperature $[80,81]$. The addition of $\mathrm{Cu}$ inhibited the hydrogenating activity of $\mathrm{Pd}$ in agreement with the low hydrogenating properties of $\mathrm{Cu}$ at low temperature, slightly decreasing the isomerization toward trans oleic isomers. The addition of $\mathrm{Pb}$ led to a significant drop of the isomerization to trans oleic derivatives. The advantage of the preparation by redox technique was to maintain the high catalytic activity for $\mathrm{C}=\mathrm{C}$ hydrogenation compared to the successive impregnation method.

\subsection{Selective hydrogenolysis}

Studies on the competitive cleavages of C-C and C-O bonds in polyols such as glycerol, glucitol (sorbitol) or erythritol in aqueous phase on metals have revealed the particular properties of copper, especially those of Raney copper. Indeed, this metal is not hydrogenolysing but is able to dehydrogenate $\mathrm{C}-\mathrm{O}$ bonds into carbonyls which are irreversibly adsorbed under reaction conditions. The nucleophilic action of surface hydroxyls on these adsorbed carbonylated derivatives leads to degradation products by cleavage of C-C and $\mathrm{C}-\mathrm{O}$ bonds. Raney copper modification with a more noble metal ( $\mathrm{M}=\mathrm{Ru}, \mathrm{Pt}, \mathrm{Au}, \mathrm{Pd})$ than $\mathrm{Cu}$ by direct redox reaction allowed one to obtain bimetallic $\mathrm{Cu}-\mathrm{M}$ systems favouring the selective cyclodehydration of polyols into more valuable furanic derivatives (Fig. 9) [5, 82].

\section{Figure 9.}

This behaviour depended on the surface atomic $\mathrm{M} / \mathrm{Cu}$ ratio and resulted from an electron transfer from $\mathrm{Cu}$ to the second metal. Bimetallic $\mathrm{Cu}-\mathrm{Pt}$ and $\mathrm{Cu}-\mathrm{Au}$ nanoparticles prepared by the same way but on charcoal support have shown catalytic properties very close to those of the previous Raney copper based systems [83].

\section{APPLICATION IN ENVIRONMENTAL CATALYSIS}

The preparation of bimetallic catalysts by surface redox reaction is well adapted for application in environmental catalysis and more particularly in nitrate removal for water treatment. The catalytic nitrate reduction in the presence of a reducing agent such as hydrogen or formic acid leads to intermediate nitrite and to either nitrogen or an undesirable product, ammonia as final product. Catalysts active for nitrate reduction are composed of (i) a noble metal, such as palladium or platinum and (ii) a transition metal such as copper, tin, indium or silver. For this application, the interaction between the noble metal and the promoter is of 
major importance. Indeed, Epron et al. [32] compared the activity of bimetallic $\mathrm{Pt}-\mathrm{Cu} / \mathrm{Al}_{2} \mathrm{O}_{3}$ catalysts with the same nominal composition but prepared according to two techniques, different by the method of introduction of copper onto the parent $\mathrm{Pt} / \mathrm{Al}_{2} \mathrm{O}_{3}$ catalyst. These techniques were (i) the catalytic reduction favouring the deposition of copper onto platinum and (ii) the impregnation by cationic exchange with the support favouring the deposition of copper onto alumina. Fig. 10 represents the disappearance of nitrate as a function of time under hydrogen in the presence of the two types of catalysts. This figure shows clearly that the most active catalyst is that prepared by catalytic reduction. It was inferred that in the bimetallic catalyst, the role of copper is to reduce nitrate into nitrite according to a redox process. In this step, the interaction between copper and platinum is of major importance to maintain copper in the metallic state by way of hydrogen adsorbed on platinum. This mechanism involves that the promoter should be easily oxidized by nitrate in the reaction conditions and then reduced by hydrogen chemisorbed on the noble metal.

\section{-Figure 10-}

Then, the preparation by catalytic reduction of multimetallic catalysts for application in water denitration was extended to other bimetallic nanoparticles such as Pt-Ag [34], Pd-Cu [32, 34, 35, 36], Pd-Sn [37], Cu-Pt [8], Cu-Pd [8] or to trimetallic nanoparticles such as Pd-Sn-Au [45], deposited on various supports.

\section{APPLICATIONS IN CATALYSIS FOR ENERGY}

\subsection{Naphtha reforming}

The reforming of low-octane feedstocks is classically carried out over bifunctional catalysts made up of a metallic nanoparticles deposited on an acidic phase. The reactions involved in this process are hydrogenation, dehydrogenation, isomerization, cyclization and hydrocracking. In the first type of naphtha reforming catalysts, the metal function was provided by platinum and the acidic one by the support itself, such as chlorinated alumina $\left(\mathrm{Pt} / \mathrm{Al}_{2} \mathrm{O}_{3}-\mathrm{Cl}\right)$. The disadvantage of this catalyst was its rapid deactivation by coking. The stability was improved with the second generation of catalysts, appeared in the late 1960's and consisting of bimetallic systems such as $\mathrm{Pt}-\mathrm{Re} / \mathrm{Al}_{2} \mathrm{O}_{3}-\mathrm{Cl}$. However, this type of catalyst must be sulphided in order to avoid the formation of undesired gaseous products.

Numerous studies were devoted to the use of bimetallic catalysts either promoted by an active metal, such as rhenium or iridium, or an inactive one, tin or germanium for example. These different catalysts were generally prepared by coimpregnation or successive 
impregnations. Moreover, most of the catalysts prepared by redox reactions were only evaluated in model reactions. For example, Corro et al. [84] prepared $\mathrm{Pt}-\mathrm{Sn} / \mathrm{Al}_{2} \mathrm{O}_{3}-\mathrm{Cl}$ by catalytic reduction or coimpregnation and compared their resistance to coking under cyclopentane feed. Thus, catalysts prepared by surface redox reaction were less sensitive than the others to deactivation. This result was explained in terms of a more effective interaction between tin and platinum when tin is introduced by catalytic reduction onto a parent platinum-based catalysts. The deactivation by coke and sulphur deposition was also studied on $\mathrm{Pt}-\mathrm{Au} / \mathrm{Al}_{2} \mathrm{O}_{3}$ catalysts prepared by catalytic reduction [85].

Some test reactions were performed under industrial-type conditions and can be considered as representative of the behaviour which could be observed in real reforming of feedstocks. For example, Pieck et al. [75] studied the catalytic performances of $\mathrm{Pt}-\mathrm{Re} / \mathrm{Al}_{2} \mathrm{O}_{3}-\mathrm{Cl}$ prepared by different methods, namely coimpregnation, successive impregnation and catalytic reduction. The catalysts were activated by calcination and then reduction. They were tested in $n$-heptane reforming, used as model reaction of paraffin dehydrocyclisation. The dehydrocyclisation is the reaction to promote since it leads to aromatics for petrochemical industry and also to a large amount of hydrogen. On the contrary, the production of gaseous products $\left(\mathrm{C}_{1}\right.$ to $\left.\mathrm{C}_{4}\right)$ must be avoided. The results obtained with the different sulphided catalysts and reported in Table 2 demonstrate that the highest conversion and yield in toluene are obtained with the catalyst prepared by catalytic reduction for which the interactions between $\mathrm{Pt}$ and $\mathrm{Re}$ are the highest. This result was explained by the increase of the dehydrogenation activity of Pt-Re entities by sulphidation. As sulphur adsorbs preferentially on rhenium, the higher the interaction between $\mathrm{Pt}$ and $\mathrm{Re}$, favoured by the preparation method, the higher the effect of sulphur.

\section{Table 2}

Recently trimetallic catalysts were prepared by redox reaction for application in naphtha reforming. Fürcht at al. modified $\mathrm{Pt}-\mathrm{Sn} / \gamma-\mathrm{Al}_{2} \mathrm{O}_{3}$ by addition of Te, $\mathrm{Bi}$ [86] or $\mathrm{Au}$, Ir and $\mathrm{Pd}$ [87] by the refilling method. Their catalysts were evaluated in n-octane reforming under industrial conditions. As reported in [43,44], it could be advantageous to replace the sulphidation step by the addition of an inactive element such as germanium or tin on a bimetallic Pt-Re or Pt-Ir catalyst. Indeed, the presence of tin or germanium instead of sulphur leads to more stable catalysts with a higher yield in $n$-heptane dehydrocyclisation under industrial-type conditions. For example, the conversion of $n$-heptane and the yield in toluene are reported on Fig. 11 as a function of the tin content in trimetallic Pt-Ir-Sn/ $\mathrm{Al}_{2} \mathrm{O}_{3}-\mathrm{Cl}$ 
catalysts, and compared with those obtained with a presulphided bimetallic catalyst, without tin. These results show that the conversion is close to $100 \%$ for all the catalysts after $5 \mathrm{~h}$ but decreases down to around $50 \%$ in the worst case after $65 \mathrm{~h}$ of reaction. This deactivation, mainly due to the presence of coke, is less important for trimetallic catalysts with a low tin content (less than $0.3 \mathrm{wt} . \%$ ) than for the presulphided bimetallic catalyst. In the same way, a strong decrease of the toluene yield occurs between $5 \mathrm{~h}$ and $65 \mathrm{~h}$ of reaction. However, the highest toluene yields are obtained with trimetallic catalysts with less than 0.4 wt.\% of tin.

-Figure 11 -

\subsection{Fuel cells}

One of the drawbacks to the development of Proton Exchange Membrane Fuel Cells using reformed fuels is the presence of $\mathrm{CO}$ in the reformate which drastically decreases the performance by poisoning of the anodic catalyst. Tolerance to a high $\mathrm{CO}$ concentration would certainly help to simplify the reformer and especially the hydrogen purification system. This simplification would lead to the reduction of the cost of the system which is the main challenge to enter the market. Accordingly, the preparation of bi and trimetallic catalysts by surface redox reaction was investigated by adding modifiers (such as $\mathrm{Ru}, \mathrm{Sn}$ and $\mathrm{Mo}$ ) on a $\mathrm{Pt} / \mathrm{C}$ based system commonly used both as an anode or a cathode catalyst but having a very poor $\mathrm{CO}$ tolerance [73]. Among the bimetallic samples, the best results were obtained with the Pt-Sn/C systems prepared by catalytic reduction. Moreover, the modification of Pt-Ru nanoparticles by $\mathrm{Sn}$ or Mo showed better $\mathrm{CO}$ tolerance than the corresponding bimetallic catalysts, with a significant enhancement of the stability in the case of Mo.

\section{CONCLUSION}

The preparation of supported multimetallic nanoparticles by redox reaction allows one to favour the interaction between the different metals, in agreement with the theoretical predictions. Nevertheless the presence of the support must be taken into account since the modifier could have a strong affinity for it. In this chapter, it is demonstrated that the operating conditions can be controlled in order to minimize the deposition of the modifier onto the support, such as the $\mathrm{pH}$ of the solution, the nature of the reducing agent or of the precursor salt...Furthermore, it is pointed out that, once the multimetallic nanoparticles are formed, they could be sensitive to external parameters, as for example the gaseous treatments, the exposure to air and so on, leading to different catalytic performances. Finally, the different applications presented in this chapter demonstrate that for a same metal loading, 
metallic nanoparticles prepared by redox reaction presentmore interesting properties than their counterpart prepared by classical techniques. Illustration are given in several areas like catalysis for organic chemical synthesis, for environment and for energy.

\section{$\underline{\text { References }}$}

[76] S.M. Augustine, W.M.H. Sachtler, J. Catal., 1987, 106, 417.

[77] S.M. Augustine, W.M.H. Sachtler, J. Phys. Chem., 1987, 91, 5953.

[65] R. Bachir, E. Lafitte, P. Marecot, B. Didillon, J. Barbier, J. Chim. Phys., 1997, 94, 19061913.

[66] R. Bachir, P. Marecot, B. Didillon, J. Barbier, Appl. Catal. A., 1997, 164, 313-322.

[67] R. Bachir, A. Reguig, P. Marecot, J. Barbier, J. Société algérienne de chimie, 2002, 12, 233-241.

[63] I. Bakos, S. Szabo, Electrochimica Acta, 2001, 46, 2507-2513.

[23] I. Bakos, S. Szabo and F. Nagy, T. Mallat and Z. Bodnar, Electroanal. Chem, 1991, 309, 293-301.

[56] I. Bakos, S. Szabo, React. Kinet. Catal. Lett., 1990, 41, 53-57.

[64] I. Bakos, S. Szabo, J. Electroanal. Chem., 2003, 547, 103-107.

[8] N. Barrabes, J. Just, A. Dafinov, F. Medina, J.L.G. Fierro, J.E. Sueiras, P. Salagre, Y. Cesteros, Appl. Catal. B, 2006, 62, 77-85.

[24] Z. Bodnar, T. Mallat, I. Bakos, S. Szabo, Z. Zsoldos, Z. Schay, Appl. Catal. A, 1993, $102,105-123$.

[3] J. Barbier, Catalytica Studies Division, Advances in Catalysts Preparation, study number $4191 \mathrm{CP}, 1992$.

[6] J. Barbier, J.C. Ménézo, C. Montassier, J. Naja, G. Del Angel, J.M. Dominguez, Catal. Letters, 1992, 14, 37-43.

[9] J. Barbier, P. Marecot, G. Del Angel, P. Bosch, J.P. Boitiaux, B. Didillon, J.M. Dominguez, I. Schifter, G. Espinosa, Appl. Catal. A, 1994, 116, 179-186.

[4] J. Barbier, in Handbook of Heterogeneous Catalysis, Vol.2 (Eds G. Ertl, H. Knözinger, J. Wertkamp) Wiley-VCH, Weinheim, pp 257-264, 1997.

[31] J. Barbier, P. Marecot, C.L. Pieck, Studies in Surface Science and Catalysis (Catalyst Deactivation), 1997, 111, 327-334.

[10] V. Bertin, P. Bosch, G. Del Angel, R. Gomez, J. Barbier, P. Marecot, J. Chim. Phys., 1995, 92, 120-33. 
[72] M. Bonarowska, J. Pielaszek, W. Juszczyk, Z. Karpinski, J. Catal., 2000, 195, Issue 2, 304-315.

[44] M. Boutzeloit, V.M. Benitez, C. Especel, F. Epron, C.R. Vera, C.L. Pieck, P. Marecot, Catal. Communications, 2006, 7, 627-632.

[52] M.W. Breiter, J. Electrochem. Soc. Electrochem. Sci., 1967, 114, 1125-1129.

[53] M.W. Breiter, Trans. Far. Soc., 1969, 65, 2197-2205.

[42] C. Carnevillier, F. Epron, P. Marecot, Appl. Catal. A, 2004, 275, 25-33.

[84] G. Corro, P. Marecot, J. Barbier, Studies in Surface Science and Catalysis (Catalyst Deactivation), 1997, 111, 359-366.

[57] A.I. Danilov, E.B. Molodkina, Y.M. Polukarov, Russ. J. Electrochem., 1998, 34, 12491256.

[79] G. Del Angel, R. Melendrez, V. Bertin, J.M. Dominguez, P. Marecot, J. Barbier, Stud. Surf. Sci. Catal., 1993, 78, 171.

[11] P. Del Angel, J.M. Dominguez, G. Del Angel, J.A. Montoya, E. Lamy-Pitara, S. Labruquere, J. Barbier, Langmuir, 2000, 16, 7210-7217.

[68] A. Douidah, P. Marecot, S. Labruquere, J. Barbier, Appl. Catal. A, 2001, 210, Issues 1-2, 111-120.

[70] A. Douidah, P. Marecot, J. Barbier, Appl. Catal. A, 2002, 225, Issues 1-2, 11-19.

[71] A. Douidah, P. Marecot, S. Szabo, J. Barbier, Appl. Catal. A, 2002, 225, Issues 1-2, $21-$ 31.

[39] J.M. Dumas, C. Geron, H. Hadrane, P. Marecot, J. Barbier, J. Mol. Catal., 1992, 77, 8798.

[14] J.M. Dumas, S. Rmili, J. Barbier, J. Chim. Phys., 1998, 95, 1650-1665.

[43] F. Epron, C. Carnevillier, P. Marecot, Appl. Catal. A, 2005, 40, 157-169.

[32] F. Epron, F. Gauthard, C. Pineda, J. Barbier, J. Catal., 2001, 198, 309-318.

[33] F. Epron, F. Gauthard, J. Barbier, Appl. Catal. A., 2002, 237, 253-261.

[73] S. Escribano, R. Mosdale, P. Marecot, P. Korovtchenko, G. Lafaye, J. Barbier, "CO tolerance of multi-metallic platinum based catalysts", Proceedings "France -Deutschland Fuel Cell Conference 2002", oct 7-10, p10, Forbach (2002).

[85] G. Espinosa, G. Del angel, J. Barbier, P. Marecot, I. Schifter, Studies in Surface Science and Catalysis (Catalyst Deactivation), 1997, 111, 421-426.

[16] G. Espinosa, G. Del Angel, J. Barbier, P. Bosch, V. Lara, D. Acosta, J. Mol. Catal. A, 2000, 164, 253-262.

[86] A. Furcht, A. Tungler, S. Szabo, A. Sarkany, Appl. Catal. A., 2002, 226, 155-161. 
[87] A. Furcht, A. Tungler, S. Szabo, Z. Schay, L. Vida, I. Gresits, Appl. Catal. A., 2002, 231, 151-157.

[51] N. Furuya, S. Motoo, J. Electroanal. Chem., 1979, 98, 195-202.

[54] N. Furuya, S. Motoo, J. Electroanal. Chem., 1976, 72, 165-175

[59] N. Furuya, S. Motoo, J. Electroanal. Chem., 1977, 78, 243-256.

[60] N. Furuya, S. Motoo, J. Electroanal. Chem., 1978, 88, 151-160.

[37] A. Garron, K. Lazar, F. Epron, Appl. Catal. B, 2005, 57, 57-69.

[45] A. Garron, K. Lazar, F. Epron, Appl. Catal. B, 2006, 65, 240-248.

[34] F. Gauthard, F. Epron and J. Barbier, J. Catal., 2003, 220, 182-191.

[47] H. Gerischer, D.M. Kolb, M. Pazasnyski, Surf. Sci., 1974, 43, 662-666.

[46] D.M. Kolb, M. Przasnyski, H. Gerischer, J. Electroanal. Chem., 1974, 54, 25-38.

[48] D.M. Kolb, in Advances in electrochemistry and Electrochemical Engineering, (Eds. M. Gerischer, C.N. Tobias), John Wiley and Sons, New-York, 1975.

[40] G. Lafaye, C. Micheaud-Especel, C. Montassier, P. Marecot, Appl. Catal. A, 2002, 230, 19-30.

[41] G. Lafaye, T. Ekou, C. Micheaud-Especel, C. Montassier, P. Marecot, Appl. Catal. A, 2004, 257, 107-117.

[78] G. Lafaye, C. Mihut, C. Especel, P. Marecot, M. Amiridis, Langmuir, 2004, 20(24), 10612-10616.

[74] Brevet Manu.

[55] E. Lamy, J. Barbier, C. Lamy, J. Chim. Phys., 1980, 77, 967-972.

[61] E. Lamy-Pitara, L. El Quazzani-Benhima and J. Barbier, J. Electroanal. Chem.,1992, 335, 363-370.

[62] E. Lamy-Pitara, L. El Ouazzani-Benhima, J. Barbier, M. Cahoreau, J. Caisso, J. Electroanal. Chem., 1994, 372, 233-242.

[50] E. Lamy-Pitara, J. Barbier, Appl. Catal. A, 1997, 149, 49-87.

[49] E. Leiva, Electrochimica Acta, 1996, 41, 2185-2206.

[69] D.R. Lide (Ed.), CRC Handbook Of Chemistry and Physics, 75th Edition, CRC Press, Boca Raton, FL, 1994/1995.

[58] D.L. Lu, M. Ichihara, K.I. Tanaka, Electrochim. Acta., 1998, 43, 2325-2330.

[1] J. Margitfalvi, S. Szabo, F. Nagy, Studies in Surface Science and Catalysis, (Catal. Hydrogenation), 1986, 27, 373-409.

[15] R. Melendrez, G. Del Angel, V. Bertin, M.A. Valenzuela, J. Barbier, J. Mol. Catal. A, 2000, 157, 143-149. 
[13] J.C. Ménézo, M.F. Denanot, S. Peyrovi, J. Barbier, Appl. Catal., 1985, 15, 353-356.

[38] J.C. Ménézo, L.C. Hoang, C. Montassier, J. Barbier, React. Kinet. Catal. Lett., 1992, 46, $1-6$.

[12] C. Micheaud, M. Guerin, P. Marecot, C. Geron, J. Barbier, J. Chim. Phys. 1996, 93, 1394-1411.

[Micheaud-1997] C. Micheaud, M. Guerin, P. Marecot, J. Barbier, J. Chim. Phys., 1997, 94, 1897-1905.

[Micheaud-1998] C. Micheaud, M. Guerin, P. Marecot, J. Barbier, Appl. Catal. A, 1998, 171, 229-239.

[5] C. Montassier, J.C. Ménézo, J. Moukolo, J. Naja, L.C. Hoang, J. Barbier, J.P. Boitiaux, J. Mol. Catal., 1991, 70, 65-84.

[7] C. Montassier, J.C. Ménézo, J. Naja, J. Barbier, J.M. Dominguez, P. Sarrazin, B. Didillon, J. Mol. Catal., 1994, 91, 107-117.

[82] C. Montassier, J.C. Ménézo, J. Naja, P. Granger, J. Barbier, P. Sarrazin, B. Didillon, J. Mol. Catal., 1994, 91, 119-128.

[83] C. Montassier, J.M. Dumas, P. Granger, J. Barbier, Appl. Catal. A, 1995, 121, 231-244.

[80] B. Nohair, C. Especel, P. Marecot, C. Montassier, L.C. Hoang, J. Barbier, C.R. Chimie, 2004, 7, 113-118.

[81] B. Nohair, C. Especel, G. Lafaye, P. Marecot, L.C. Hoang, J. Barbier, J. Mol. Catal. A, 2005, 229, 117-126.

[75] C.L. Pieck, P. Marecot, C.A. Querini, J.M. Parera, J. Barbier, Appl. Catal. A, 1995, 133, Issue 2, 281-292.

[26] C.L. Pieck, P. Marecot, J. Barbier, Appl. Catal. A, 1996, 134, 319-329.

[28] C.L. Pieck, P. Marecot, J. Barbier, Appl. Catal. A, 1996, 141, 229-244.

[29] C.L. Pieck, P. Marecot, J. Barbier, Appl. Catal. A, 1996, 143, 283-298.

[30] C.L. Pieck, P. Marecot, J. Barbier, Appl. Catal. A, 1996, 145, 323-334.

[35] J. Sa, S. Gross, H. Vinek, Appl. Catal. A, 2005, 294, 226-234.

[36] J. Sa, H. Vinek, Appl. Catal. B, 2005, 57, 247-256.

[17] S. Szabo, F. Nagy, J. Electroanal. Chem., 1977, 84, 93-98.

[18] S. Szabo, F. Nagy, J. Electroanal. Chem., 1977, 85, 339-343.

[19] S. Szabo, F. Nagy, J. Electroanal. Chem., 1978, 87, 261-265.

[25] S. Szabo, F. Nagy, Isr. J. Chem., 1979, 18, 162-165.

[20] S. Szabo, F. Nagy, J. Electroanal. Chem., 1984, 160, 299-303.

[21] S. Szabo, F. Nagy, J. Electroanal. Chem., 1987, 230, 233-240. 
24-05-06

[22] S. Szabo, I. Bakos, F. Nagy, J. Electroanal. Chem, 1989, 271, 269-277.

[Szabo-1989-2] S. Szabo, I. Bakos, F. Nagy, J. Electroanal. Chem, 1989, 263, 137-146.

[2] S. Szabo, International Reviews in Physical Chemistry, 1991, 10, 207-248.

[27] S. Szabo, I. Bakos, React. Kinet. Catal. Lett., 1998, 65, 259-263. 
Table 1. Comparison of the treatment effects on the dispersion loss of different catalysts under hydrogen and nitrogen in aqueous media during 24h [70].

\begin{tabular}{rlll}
\hline \multirow{2}{*}{ Catalysts } & \multicolumn{3}{l}{ Platinum dispersion loss (\%): 100.( $\left.\mathrm{D}_{0}-\mathrm{D}\right) / \mathrm{D}_{0}$} \\
\cline { 2 - 4 } & $\mathrm{pH}=0.7$ & $\mathrm{pH}=6$ & $\mathrm{pH}=10$ \\
\hline 1.0 wt.\% $\mathrm{Pt} / \mathrm{SiO}_{2}\left(\mathrm{D}_{0}=41 \%\right)$ & & 6 & 10 \\
under $\mathrm{N}_{2}$ & 60 & 38 & 62 \\
under $\mathrm{H}_{2}$ & 72 & & 10 \\
\hline 1.0 wt.\% $\mathrm{Pt} / \mathrm{Al}_{2} \mathrm{O}_{3}\left(\mathrm{D}_{0}=45 \%\right)$ & & 0 & \\
under $\mathrm{H}_{2}$ & 0 & &
\end{tabular}

Table 2. $n$-heptane $\left(n \mathrm{C}_{7}\right)$ conversion (at $\left.30 \mathrm{~min}\right)$, yields in toluene and gaseous products $\left(\mathrm{C}_{1}\right.$ to $\mathrm{C}_{4}$ ) obtained with sulphided $\mathrm{Pt}-\mathrm{Re} / \mathrm{Al}_{2} \mathrm{O}_{3}-\mathrm{Cl}(0.6 \mathrm{wt} \% \mathrm{Pt}, 0.5$ wt.\% $\mathrm{Re}$ ) prepared by coimpregnation (CI), successive impregnations (SI) or catalytic reduction (CR). (Reaction conditions : $\mathrm{T}=500^{\circ} \mathrm{C}, \frac{\mathrm{H}_{2}}{n \mathrm{C}_{7}} \approx 6$ (molar ratio), $\mathrm{P}=10 \mathrm{bar}$, WHSV $=2.9 \mathrm{~h}^{-1}$ ) [Pieck-1995]

\begin{tabular}{cccc}
\hline Preparation method & Conversion (\%) & Toluene (\%) & C1 to C4 (\%) \\
\hline CR & 96.5 & 27.5 & 32 \\
SI & 79 & 17 & 30 \\
CI & 85 & 21.5 & 25 \\
\hline
\end{tabular}




\section{Figure Captions}

Figure 1. Time distribution of (- $\mathrm{Cu}$ ion and ( $(\circ) \mathrm{Pt}$ ion concentrations in solution during the preparation of $\mathrm{Cu}-\mathrm{Pt}$ by direct redox reaction, with an initial atomic ratio $\mathrm{Pt}^{4+} / \mathrm{Cu}_{\mathrm{S}}=57(2 \mathrm{~g}$ of Raney $\mathrm{Cu}, 100 \mathrm{~mL}$ of solution) [9].

Figure 2. Wt.\% Ge deposited by catalytic reduction over (•) Rh/silica and (•) Rh/alumina as a function of the wt.\% Ge introduced in solution [40].

Figure 3. Cyclopentane hydrogenolysis $\left(10^{-2} \mathrm{~mol}\right.$ converted per second and per gram of $\left.\mathrm{Pt}\right)$ on Pt-Re catalysts prepared by catalytic reduction in $\mathrm{HNO}_{3}$ medium: (-) catalysts activated by reduction (hydrogen, $\left.8 \mathrm{hrs}, 500^{\circ} \mathrm{C}\right) ;(\bullet)$ catalysts activated by calcination (air, 4 hrs, $450^{\circ} \mathrm{C}$ ) and then reduction (hydrogen, $8 \mathrm{hrs}, 500^{\circ} \mathrm{C}$ ) [29].

Figure 4. TPR profiles of alumina supported catalysts, oxidized $12 \mathrm{~h}$ under flowing oxygen at $400^{\circ} \mathrm{C}$ : (a) 1 wt. $\% \mathrm{Cu}$; (b) 3 wt. $\% \mathrm{Pt}$ and (c) 3 wt. $\%$ Pt-1 wt. $\% \mathrm{Cu}$ prepared by catalytic reduction.

"Reprinted from, Applied Catalysis A, Vol. 237, F.Epron, F. Gauthard, and J. Barbier, Influence of oxidising and reducing treatments on the metal-metal interactions and on the activity for nitrate reduction of a Pt-Cu bimetallic catalyst, Pages 253-261, Copyright (2002), with permission from Elsevier".

Figure 5. TEM image and metal particle size distribution of a $20 \mathrm{wt} . \%(\mathrm{Pt}+\mathrm{Ru}) 1.8 \mathrm{wt} . \% \mathrm{Mo}$ / C catalyst prepared by catalytic reduction.

Figure 6. Simplified reaction scheme for carvone hydrogenation

Figure 7. Simplified reaction scheme for citral hydrogenation

Figure 8. Selectivities for $\mathrm{Rh}-\mathrm{Ge} / \mathrm{SiO}_{2}$ (a) and $\mathrm{Rh}-\mathrm{Ge} / \mathrm{Al}_{2} \mathrm{O}_{3}$ (b) catalysts prepared by surface redox reaction at $50 \%$ citral conversion $\left(\mathrm{T}_{\text {reaction }}=70^{\circ} \mathrm{C}, \mathrm{P}_{\mathrm{H} 2}=76\right.$ bar, isopropanol as solvent):

(•) citronellal; ( $\mathbf{\Delta})$ unsaturated alcohols; $(\bullet)$ citronellol

Figure 9. Examples of polyol conversion into furanic derivatives

Figure 10. Nitrate concentration versus time in the presence of $\mathrm{Pt}-\mathrm{Cu} / \mathrm{Al}_{2} \mathrm{O}_{3}$ catalysts prepared by catalytic reduction $(\boldsymbol{\Delta})$ or by impregnation by cationic exchange ( $\mathbf{a})$ ( 0.75 wt.\% Pt, 0.25 wt.\% $\mathrm{Cu}$, reaction conditions : nitrate source : $\mathrm{Mg}\left(\mathrm{NO}_{3}\right)_{2}, \mathrm{~T}=10^{\circ} \mathrm{C}, \mathrm{P}_{\mathrm{H} 2}=1$ bar, $\left.\mathrm{m}_{\text {cata. }}=8 \mathrm{~g} \cdot \mathrm{L}^{-1}\right)$.

"Reprinted from Journal of Catalysis, Vol.198, F.Epron, F. Gauthard, C. Pinéda and J. Barbier, Catalytic reduction of nitrate and nitrite on $\mathrm{Pt}-\mathrm{Cu} / \mathrm{Al}_{2} \mathrm{O}_{3}$ catalysts in aqueous 
solution: Role of the interaction between copper and platinum in the reaction, Pages 309318, Copyright (2001), with permission from Elsevier".

Figure 11. $n$-heptane conversion and yield in toluene obtained with trimetallic Pt-Ir$\mathrm{Sn} / \mathrm{Al}_{2} \mathrm{O}_{3}-\mathrm{Cl}$ prepared by catalytic reduction, after $5 \mathrm{~h}(\bullet)$ and $65 \mathrm{~h}(\boldsymbol{\square})$ or presulphided bimetallic Pt-Ir/ $/ \mathrm{Al}_{2} \mathrm{O}_{3}$ catalyst after $5 \mathrm{~h}(\times)$ or $65 \mathrm{~h}$ (*) of reaction ( $0.3 \mathrm{wt} . \% \mathrm{Pt}, 0.3 \mathrm{wt} . \%$ Ir, reaction conditions : $\mathrm{T}=500^{\circ} \mathrm{C}, \frac{\mathrm{H}_{2}}{n \mathrm{C}_{7}}=3$ (molar ratio), $\mathrm{P}=5 \mathrm{bar}$, WHSV $=2 \mathrm{~h}^{-1}$ ). 


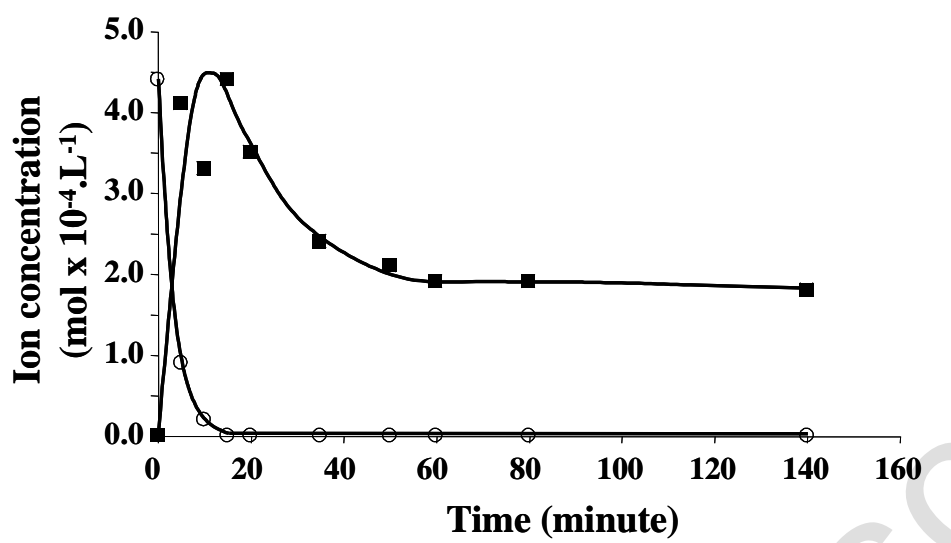

Figure 1. 


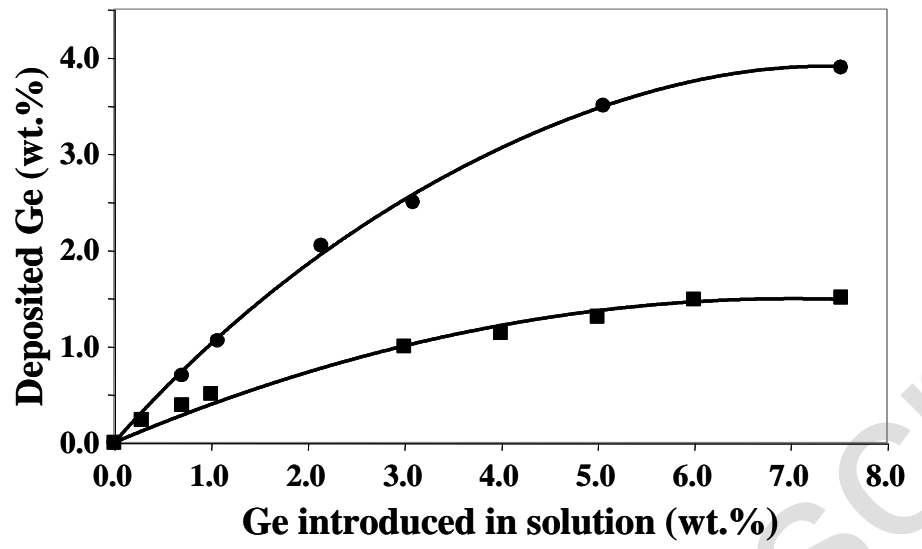

Figure 2. 


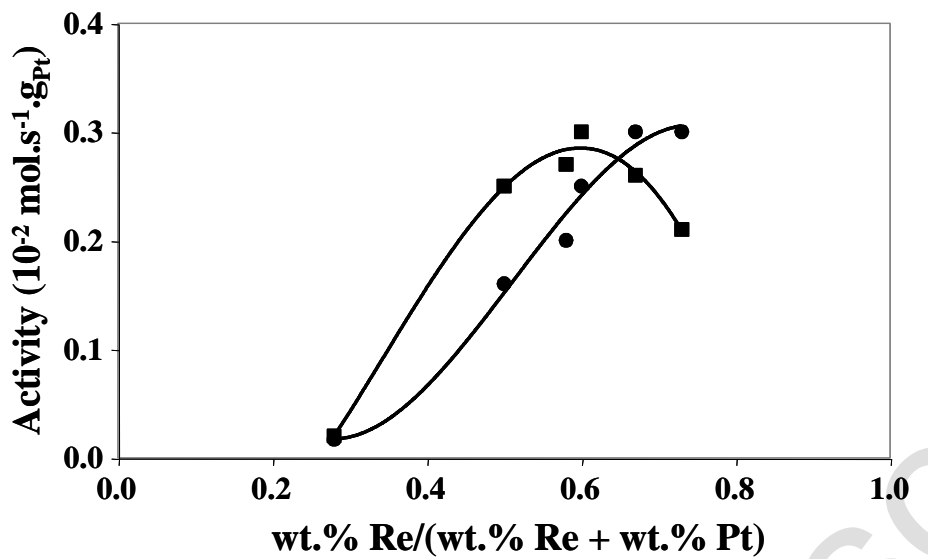

Figure 3. 


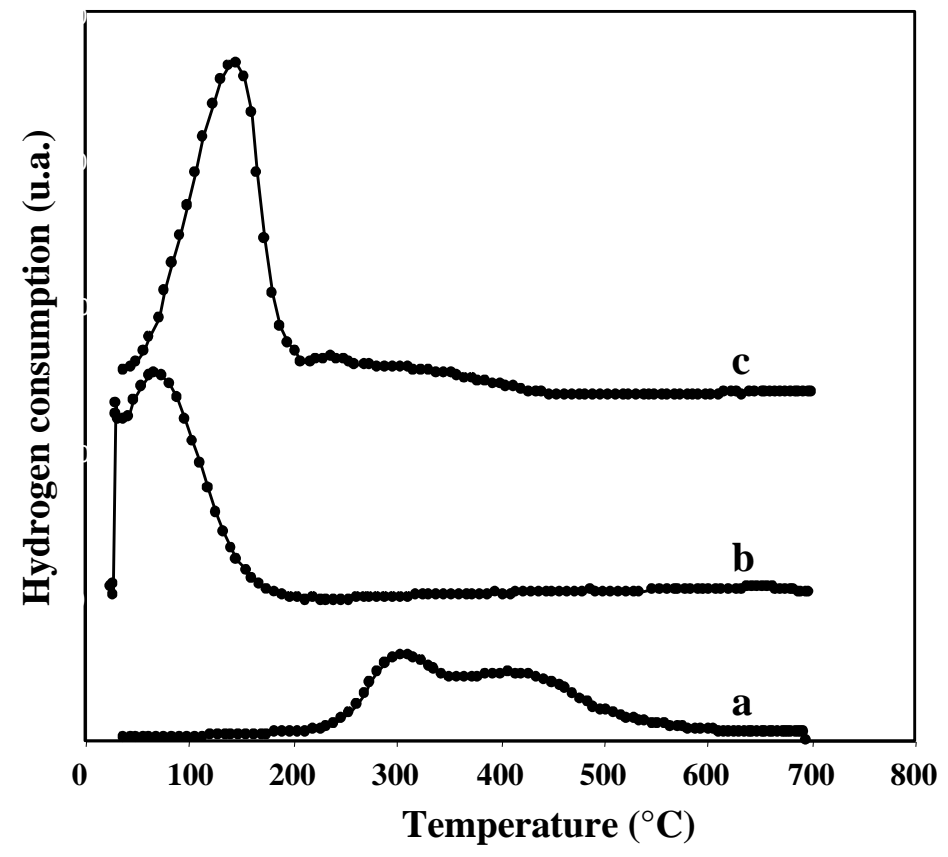

Figure 4. 
24-05-06

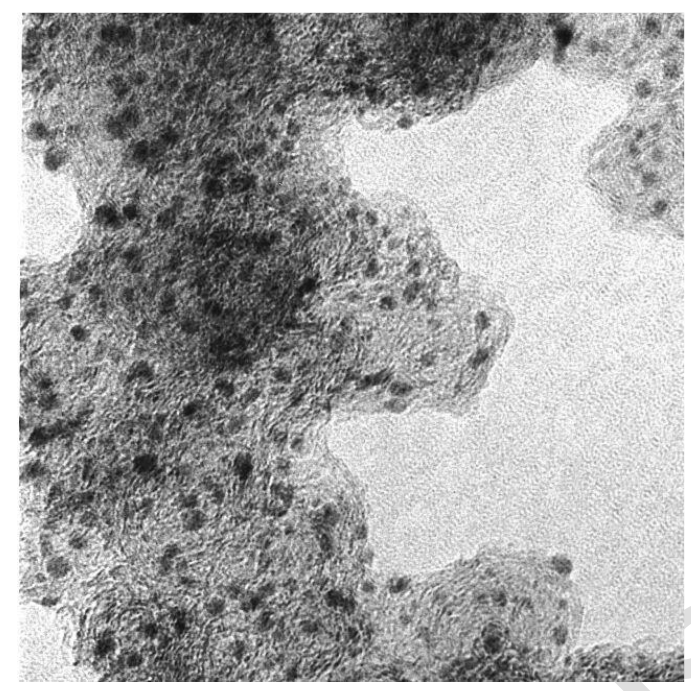

Figure 5. 


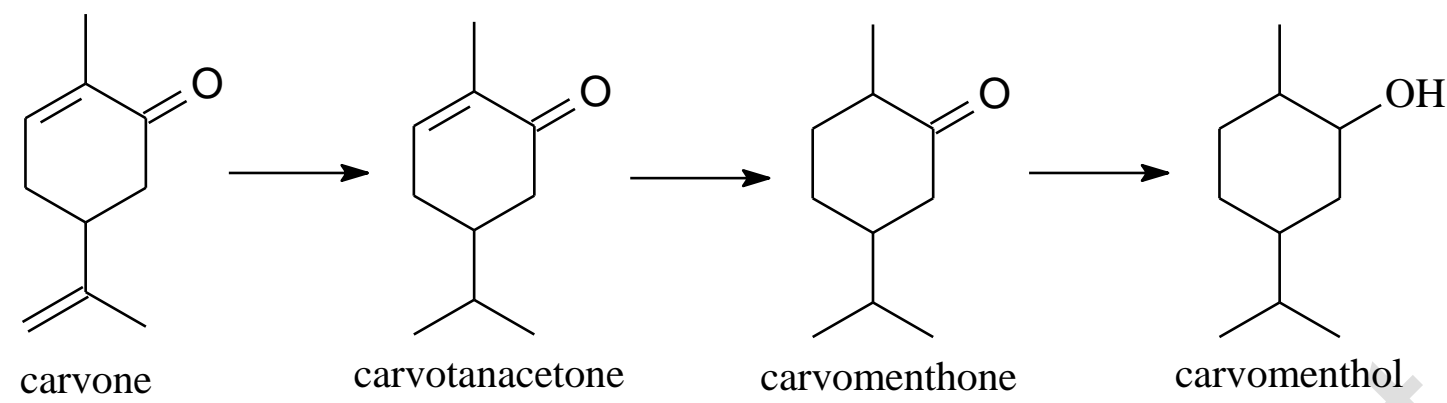

Figure 6. 


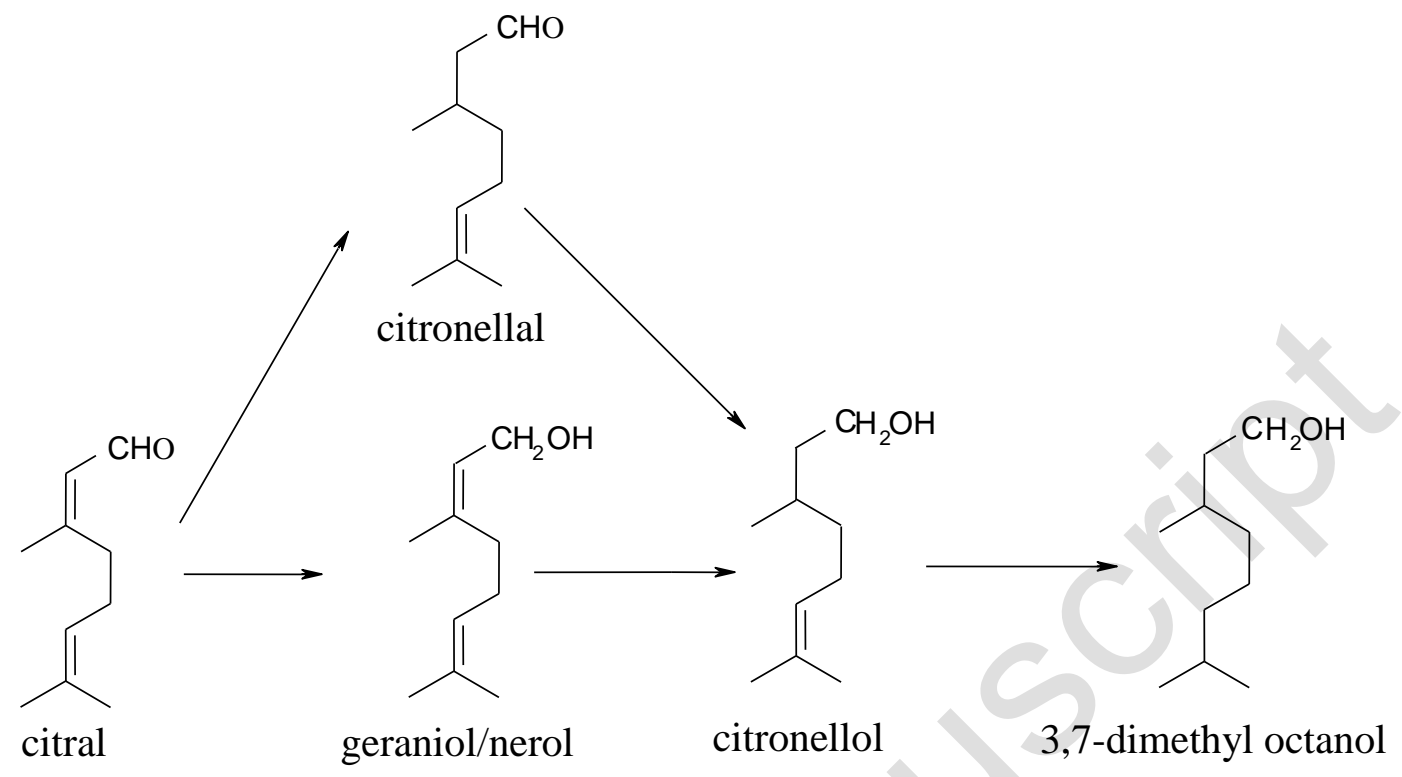

Figure 7 

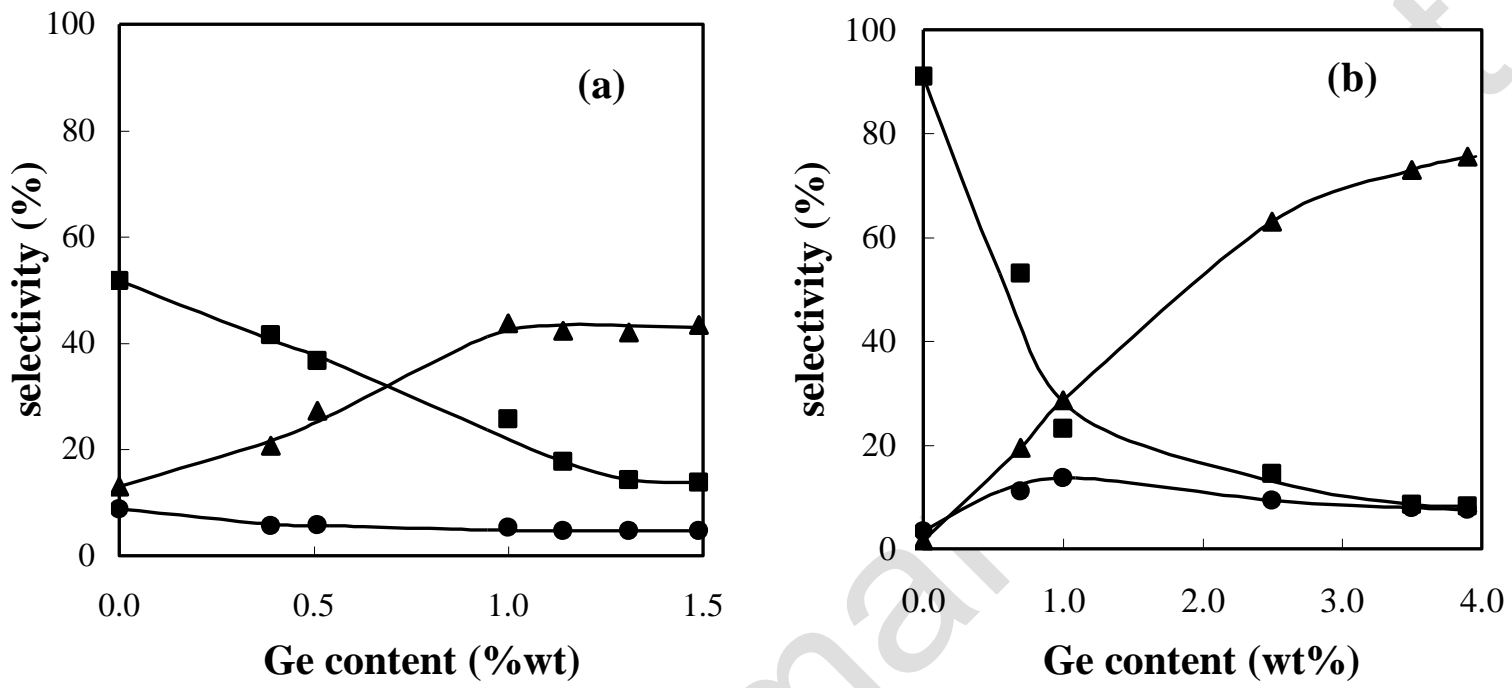

Figure 8 


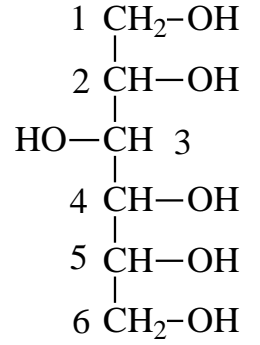

glucitol

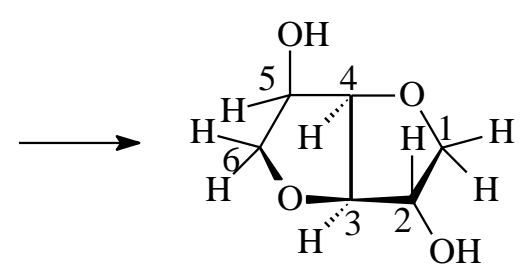

isosorbide

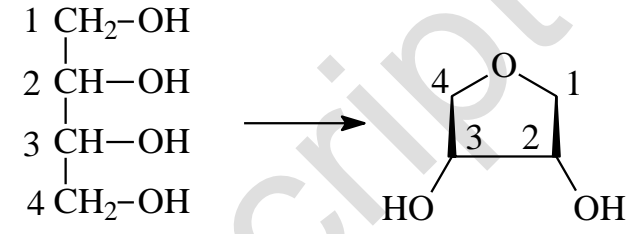

erythritol 1-4-anhydroerythritol

Figure 9 


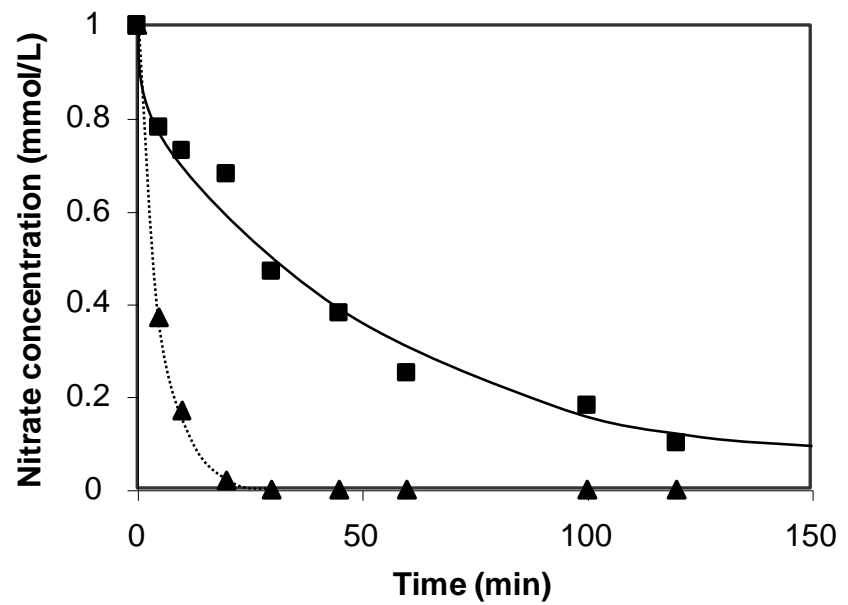

Figure 10 

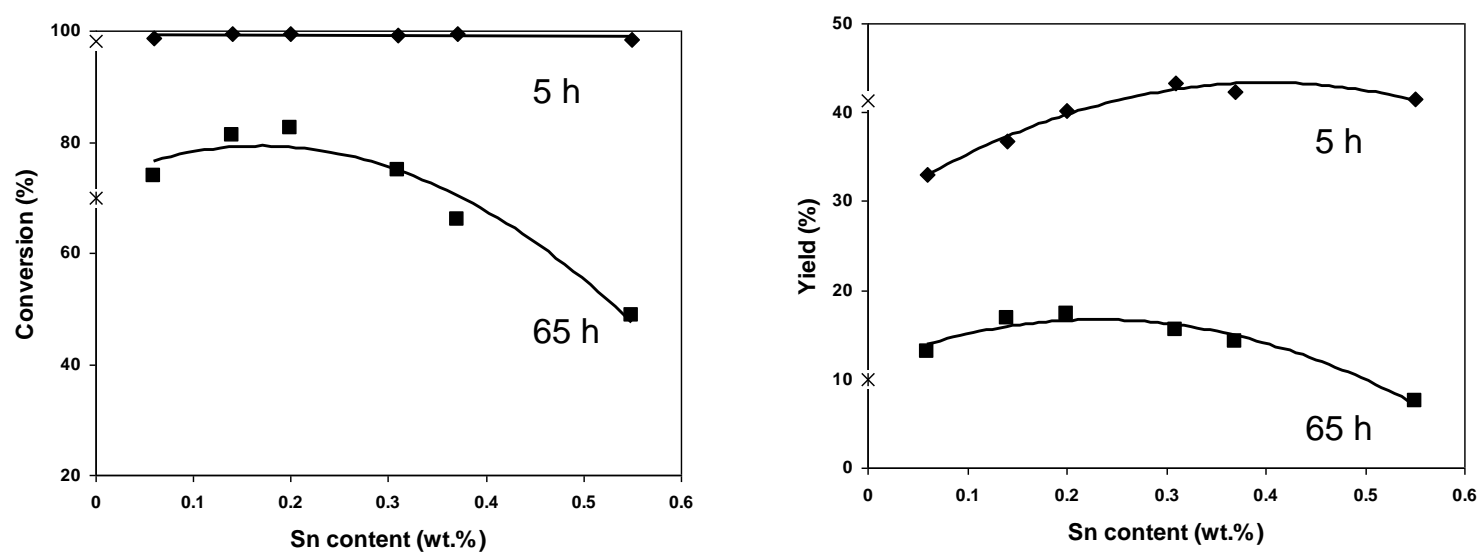

Figure 11 
24-05-06 